\title{
Who does what in enabling ambidexterity? Individual Actions and HRM practices
}

Juani Swart, Neil Turner, Yvonne van Rossenberg \& Nicholas Kinnie

\begin{abstract}
In this paper we explain how ambidexterity, the simultaneous pursuit of exploration and exploitation, is enabled at the individual level of analysis. Research on ambidexterity has been dominated by theoretical approaches focusing on the organisational level, however we know little about how ambidexterity is enacted by employees. There is also limited work on the multilevel aspects of individual employee actions, e.g., particular roles and specifically the level of seniority of the role. We address these gaps by asking: Which individual actions are undertaken by employees at particular levels of seniority in the organization to enable ambidexterity? In order to ans ........ 15442870 on we draw on previous research to construct reliable measures of the individual actions that enable ambidexterity. The hypothesized mediation effect of these individual actions is confirmed on the basis of survey data from 212 employees from a UK-based Professional Service Firm. The findings indicate that senior employees are more likely to use 'integration', 'role expansion' and 'tone setting', whilst employees with specialist knowledge about their clients use 'gap filling' to enable ambidexterity. Finally, we draw together these findings with 35 interviews conducted to present the HRM practices which support ambidexterity.
\end{abstract}

Key words: ambidexterity, multilevel, individual actions, levels of seniority, professional services firms.

\footnotetext{
Published by Taylor and Francis. This is the Author Accepted Manuscript issued with: Creative Commons Attribution Non-Commercial License (CC:BY:NC 4.0).

The final published version (version of record) is available online at DOI:10.1080/09585192.2016.1254106. Please refer to any applicable publisher terms of use.
} 


\section{Introduction}

Organizations have both to innovate and refine existing products and solutions if they are to survive and thrive in competitive economic environments (Li et al., 2013). The ability to achieve ambidexterity has been a key theme within the literature since March (1991) introduced the concepts of exploration and exploitation. However, the majority of the research on ambidexterity has been conducted at the organizational level (Turner, Swart and Maylor, 2013), with limited work on how it is enabled by complex combinations of behaviours at various levels. In any organization, regardless of its size or networked structure (Swart and Kinnie, 2014), ambidexterity relies on individual employees becoming and remaining engaged in the innovative processes at work (Janssen et al., 2004; Scott, 1995; Caniels and Veld, 2016), yet our knowledge of the actions required to enable ambidexterity, and the subsequent implications for HRM practices, is still inadequate.

It is also important to take into account that individuals at different levels of seniority in an organization will undertake different types of actions when exploring and exploiting. It is therefore surprising that there is limited research to date that considers the actions undertaken by individuals who have specific roles at particular levels of seniority. This lack of current knowledge has serious implications for HRM scholars given that it directly impacts on our theoretical development of how job design, resourcing, development and reward of individuals can impact on ambidexterity. The link between individual actions, levels of seniority and the enablement of ambidexterity is central to the hypothesized model in our paper. Importantly, we need to be able to answer the question: Which individual actions are undertaken by employees at particular levels of seniority in the organization to enable ambidexterity? if we are to understand the implications for the link between HRM practices and ambidexterity. 
In answering this research question we build upon prior research that has been valuable in identifying which behaviours enable ambidexterity. In addition we fill the gap which Andriopoulos and Lewis (2009) point to and aim to indicate which employees, at specific levels of seniority, undertake particular actions in their ambidextrous pursuits. This would be important to identify given that it has direct implications for HRM practices which enable ambidexterity.

In order to answer this question we structure the paper as follows. Firstly we review the literature on ambidexterity and identify the position of this within HRM research. We point in particular to the lack of research, in this body of literature, on the individual actions that enable ambidexterity. We illustrate the need to connect levels of seniority of employees to the actions that support the enactment of ambidexterity to develop HRM theory further. This provides the rationale for the hypothesized model, which is tested in the empirical part of this paper. The interconnection between individual actions at specific levels of seniority and the enablement of ambidexterity has very specific theoretical and practical HRM implications which we discuss in detail.

In the second section we discuss how we gathered our data and in particular how we developed our measures on the individual actions that enable ambidexterity. Thereafter the hypothesized model is tested and results presented. These results illustrate that we are able to pinpoint the exact nature of the individual actions that are used at specific levels of seniority in the organization. Thirdly, we discuss the findings and consider the impact of individual actions at various levels on the ability of the firm to be ambidextrous. Finally, we link our findings on the particular roles, levels of seniority and individual actions to develop an HRM framework that enables ambidexterity. 
In summary, we focus on the individual level of analysis to understand which actions enable ambidexterity. This allows us to make specific contributions to the HRM and ambidexterity literatures. Firstly, we identify and develop a reliable measure of individual actions that enable ambidexterity. Secondly, we are able to confirm the hypothesized mediation model, gaining insight into how the levels of seniority link to these actions that enable ambidexterity. Thirdly, we develop an empirically-grounded HRM framework that supports ambidexterity by illustrating how resourcing, development, performance and reward practices enable ambidexterity.

\section{Literature on ambidexterity}

March (1991) introduced the twin requirements of exploitation, involving "refinement, choice, production, efficiency, selection, implementation, execution" (1991:71) and exploration, characterised by "search, variation, risk taking, experimentation, play, flexibility, discovery, innovation" (1991:71). This framed the practical organizational challenge that has occupied scholars and practitioners since its publication. It sets up an inherent tension if, as March (1991) suggests, these two activities compete for finite resources. Levinthal and March (1993) contend that excessive focus on exploitation may lead to short-term benefit, but at the cost of long-term viability if the organization fails to adapt to evolving market requirements. Similarly, extensive exploration activities (necessarily risky and uncertain ventures) may be at the expense of shorter-term actions necessary for survival.

A growing body of literature, though, shows that ambidextrous organizations can in fact manage both successfully, and this is generally associated with financial and other performance benefits (see Birkinshaw and Gupta, 2013; Junni, et al., 2013; Turner et al., 2013; and O'Reilly and Tushman, 2013, for reviews). The utility of ambidexterity is broadly accepted, yet despite the burgeoning number of studies, there is only limited explanatory 
empirical evidence of how ambidexterity can be achieved, and the specific individual actions needed to bring it about. This has particular implication for HRM practices since these will be instrumental in enabling organizational ambidexterity.

The detailed mechanisms by which ambidexterity can be implemented, i.e. the methods by which exploitation and exploration can be balanced, are still far from clear, and overcoming this is a paradox to be considered at all levels of the organization (Andriopoulos and Lewis, 2009). Currently we know about three major approaches to achieving ambidexterity (Turner et al., 2013). In temporal ambidexterity (Tushman and O'Reilly, 1996), exploitation and exploration are sequential, i.e. the organization switches from one mode to the other depending upon market requirements. For example, a stable operational structure may be forced into rapid change by the actions of a new competitor. In structural ambidexterity (O'Reilly and Tushman, 2004), however, the organization is configured to support both exploitation and exploration through the separation of these processes into different departments or business units. Current operations might thus be separated from the R\&D activities, since these require different operational procedures. These conflicting requirements are integrated at the senior management level (Raisch and Birkinshaw, 2008), where there is the clearest view of the organizational strategy and resources can be allocated most effectively. The third model is that of contextual ambidexterity (Gibson and Birkinshaw, 2004), which is "the behavioral capacity to simultaneously demonstrate alignment [exploitation - meeting defined goals] and adaptability [exploration - reconfiguration as required at that moment in time] across an entire business unit.” (2004:209).

This is based on the premise that individuals can make their own judgements on how best to spend their time and resolve the potentially contradictory demands in each specific work situation. Each of these options must be supported by an appropriate HR system. 
The literature on ambidexterity is characterised by theoretical work and the empirical studies undertaken, although they cover a wide range of industries, are primarily at the organizational level (Cegarra-Navarro and Dewhurst, 2007; Turner et al., 2013). Although the role of the individual manager is acknowledged as important (e.g. Birkinshaw and Gupta, 2013; Dover and Dierk, 2010; Lubatkin, Simsek, Ling and Veiga, 2006; Mom, Van den Bosch and Volberda, 2007, 2009; Nemanich and Vera, 2009), there is only limited work on the microfoundations of ambidexterity, i.e. the role of individual actors within the organization, and we heed the call from O'Reilly and Tushman (2011) for greater insight into this aspect. From an HRM perspective, achieving both exploitation and exploration is a challenge, yet to date we do not have a full understanding of the mechanisms by which it can be achieved.

We note that although there is a significant body of research on the role of the HRM in generating ambidexterity, there remains a need to understand how ambidexterity is enacted at the individual level and how this is related to levels of seniority. In this review we discuss the analysis of ambidexterity within the HRM literature, which we categorise into the following themes (i) The characteristics of HRM systems, such as high-performance, high involvement; and flexibility which supports ambidexterity; (ii) the importance of including multiple levels of analysis when unpicking the links between HRM and ambidexterity, and (iii) following on from the multiple levels, the prominence of the intellectual capital frameworks in HRMAmbidexterity research. This lays the foundation for being able to take an individual level perspective which underpins our empirical work.

\section{Ambidexterity: HRM systems and their characteristics}

The importance of HRM practices in enabling ambidexterity is evident within the literature (Renzl, Rost and Kaschube, 2013). The paradox of accommodating both exploitation and exploration is taken up by Yoon and Chae (2012) who define its management as 
"managerial and organizational practices that realize the simultaneous accomplishment of equally desirable, multiple strategic objectives that are seemingly or actually incompatible" (p. 3502). Their empirical work showed that firms which could manage both efficiency and innovation incorporated effective paradoxical practices: employing both decentralisation and control, together with the HR practices of market mechanisms for rewards, bureaucratic mechanisms for stability and clan mechanisms encouraging a sense of membership. They incorporate a 'bottom-up' approach, acknowledging that these principles need to penetrate the psychology of all the organizational members, as opposed to other studies which focus on a top-down senior management perspective. The reward aspect is also addressed by Ahammad et al. (2015) who examine the impact of both ex-ante incentives (incentives based on past performance) and ex-post incentives (incentives based on future performance) on the productivity, motivation, and performance of employees. They focus on how motivationenhancing HR practices such as incentive schemes impact upon a positive sense of stretch that is essential for ambidexterity.

Similarly, Prieto and Pilar Pérez Santana (2012) use a Spanish study to identify that an HRM system characterized by high-involvement which shapes the organizational social climate in turn affects the firm's ambidextrous learning and its subsequent performance. PrietoPastor and Martin-Perez (2015) additionally identify that high-involvement HRM systems are positively related to ambidexterity. Paying attention to the characteristics of HRM systems, Patel et al. (2013) study the role of high-performance work systems (HPWS) as a method of enhancing organizational ambidexterity. Their data from 215 high-tech small to medium-sized enterprises showed that HPWS utilisation is positively related to organizational ambidexterity and that ambidexterity mediates the relationship between HPWS utilisation and firm growth. These high performance and involvement systems have elements of flexibility which Ketkar and Sett (2009) also advise are central to ambidexterity. Garaus et al. (2016) demonstrate 
further that ambidextrous HRM systems facilitate the continuous integration of exploitation and exploration in the pursuit of flexibility and efficiency.

By paying attention to the characteristics of HRM systems, Huang and Kim (2013) identify an architecture of HRM practices and mechanisms which lead to ambidexterity. They show how this is enacted within LG Electronics, and discuss the importance of such a capability in an increasingly turbulent and unpredictable environment. Dixon et al. (2007) also use longitudinal case studies of Russian oil majors to show how they shifted first towards a more exploitative approach and then towards a more exploratory one. The latter mode requires a more participatory management style to engage employees at all levels and hence HR has a significant part to play in such a transformation. Havermans et al. (2015) similarly examine the role of leadership and identify the necessary dynamic shifts between exploitation and exploration, indicating the role of HR in supporting this. Heavey, Simsek and Fox (2015) continue the theme of leadership in their research and identify the benefits of senior managers' social networks in conjunction with a will to innovate.

The aforementioned studies all point to (i) the importance of flexibility, often described as managing a paradox (Lewis, 2000), and (ii) the impact of HRM systems on culture (or climate). The importance of culture is also evident in other previous research which indicates that it may incorporate numerous factors, including rivalry, competition and rewards (De Clercq, Thongpapanl and Dimov, 2013, 2014), and goal harmony (Seshadri, Piderit and Giridharadas, 2010). Wang and Rafiq (2014) identify that for successful high-tech product innovation and organizational success, the culture should incorporate organizational diversity together with a shared vision. 
The attainment of ambidexterity is, however, complex and there is no 'simple' solution. Güttel and Konlechner (2009) identify key elements supporting ambidextrous organizations, including: a combination of detailed procedures and simple rules with loose-tight relationships to balance flexibility with structure; fluid, project-based, structures for rapid adaptation to new demands; and flexibility via HR systems. They also find that cultural values and social norms, shared language and mutual understanding are important in fostering contextual ambidexterity. In these organizations, projects serve as knowledge bridges, and since an employee may be a member of more than one project concurrently, he or she needs to switch between exploratory and exploitative activities based on judgement.

The above mentioned literature provides useful insight into how HRM systems may facilitate ambidexterity. However, it does not fully inform our understanding of the individual actions that support the attainment of ambidexterity. In the section that follows we therefore point to the literature on the links between multiple levels of analysis and HRM practices. This useful body of research indicate the importance of both individual and organizational level characteristics in attainting ambidexterity but what is still lacking is how individual actions intertwine across various levels of seniority in the organisation. This also forms the foundation of our hypothesized model because we are particularly interested in the impact of levels of seniority on the individual actions which enable ambidexterity.

\section{$\underline{\text { Ambidexterity - HRM and Multiple-levels of analysis }}$}

The management of ambidexterity across levels in the organization has been referred to as the management of paradoxes across levels, which becomes "the responsibility of actors throughout the firm" (Andriopoulos and Lewis, 2009: 708). Junni et al. (2015) accordingly identify multi-level HR antecedents (employee characteristics, leader characteristics and HR practices/systems) and organizational antecedents (structure, culture, social relationships and 
organizational environment) that lead to ambidexterity. Focusing on the individual level of analysis, Burgess et al. (2015) look at 'hybrid' middle managers, those staff who have both professional and managerial responsibilities. They specifically study health care, and identify how these individuals find ways of facilitating exploration and exploitation in complex environments through forging workable compromises in day-to-day activities and using effective relationships to integrate knowledge flows across different functional groups. Building on this, Xing et al. (2016) take an ambidexterity perspective on Chinese Guanxi in superior-subordinate relationships and identify how this accommodates the tension between individual career advancement and commitment to the organization. They identify this as a strategic HR asset that can be used for both personal benefit and organizational performance.

Taking a multi-level perspective, Chang (2015), finds that firm-level HPWS are positively related to unit-level employee human capital, which partially mediates the relationship between firm-level HPWS and unit-level ambidexterity. Firm-level social climate moderates the effect of firm-level HPWS on unit organizational ambidexterity through unitlevel employee human capital. She recommends further multilevel studies of the interaction among individuals and firms, including external social relationships and inter-organizational partnerships. The notion of forms of capital at various levels; i.e., human, social and organisational capital, is further evident in a growing body of research which we discuss here.

\section{Multi-level approach and the role of intellectual capital}

Kang and Snell (2009) develop a framework for HRM based on intellectual capital concepts, showing how human, social and organizational capital (HC, SC and OC, respectively) can have exploitative and exploratory aspects. Exploitative $\mathrm{HC}$ is 'specialist' knowledge, whereas exploratory HC is 'generalist'. Exploitative SC uses dense social networks to share complex concepts, its exploratory equivalent draws on a wider range of weaker ties to seek new 
knowledge. Finally, exploitative and exploratory OC can be thought of as mechanistic or organic organizational systems, respectively. They argue that these elements can be combined using different architectures deliberately to create an ambidextrous organization (see also Kang, Morris and Snell, 2007; Kang, Swart and Snell, 2012). Kostopoulos, Bozionelos and Syrigos (2015), also taking an intellectual capital approach, find that unit human and social capital positively contribute to unit ambidexterity, whereas unit organizational capital has a negative relationship with unit ambidexterity. They show that high performance HR practices amplify the former and mitigate the effects of the latter. Turner and Lee-Kelley (2013) build on Kang and Snell (2009) to show that project managers exhibit both exploitative and exploratory human, social and organizational capital (i.e. all six facets) in their work to achieve ambidexterity at the project level.

Turner et al. (2016) most closely looks at the links between individual actions and levels of seniority, i.e., project managers, superiors, subordinates and peers, when they use the intellectual capital lens to examine the achievement of ambidexterity in project team settings. They show how ambidexterity can be attained through the combination of these individuals' outputs, and identify five key individual actions that support the effective achievement of an ambidextrous balance. These actions are 'role expansion' (doing more than is normally required by the role to solve problems that arise), 'tone setting' (setting the climate and giving messages to the team about desired behaviours), 'buffering' (offering managerial 'protection' to staff so they can concentrate more effectively on their assigned tasks) and 'gap filling' (undertaking mostly administrative tasks that were otherwise not being performed). The key action was found to be 'integration' (bringing the knowledge and participants in a project team together) which was itself beneficial but was also found operating in tandem with other actions. This represents an important first step in identifying the individual actions that enable 
ambidexterity, but this study did not examine their nature with regard to the organizational hierarchy. That is how individuals at various levels of seniority enable ambidexterity.

In summary, the literature shows that there are organizational, social/relational and individual factors that lead to ambidexterity. To date we do, however, have no quantitative measures of how individual actions enable ambidexterity at various levels of seniority. We follow Junni et al. (2015) who write that "to truly uncover ambidexterity as a multilevel phenomenon, we need further research into the micro-foundations of ambidexterity at the individual and project/team levels" (S2), and this is the focus of the research we present. We therefore ask: Which individual actions are undertaken by employees at particular levels of seniority in the organization to enable ambidexterity?

In answering this research question we build upon prior research that has been valuable in identifying which behaviours enable ambidexterity. In addition we fill the gap which Andriopoulos and Lewis (2009) point to and aim to indicate which employees, at specific levels of seniority, undertake particular actions in their ambidextrous pursuits. This would be important to identify given that it has direct implications for HRM practices which enable ambidexterity. In order to gain insight into the individual actions that enable ambidexterity, this paper examines the relationship between the level of seniority of employees, individual actions and ambidexterity. We expect that level of seniority will affect ambidexterity in a direct way, however we are particularly interested in unpacking the mediation effect assessing how individual actions enable ambidexterity.. This results in the hypothesized model depicted in Figure 1.

[Include Figure 1 about here] 


\section{Research Methods and Analysis}

\section{Analytical strategy}

In order to empirically test the individual actions that enable ambidexterity hypothesized in our model (Figure 1) there were two steps in the methodology. First, a survey instrument was developed from the explorative work by Turner et al. 2016. The construct validity and reliability of this set of five latent constructs was assessed using Confirmatory Factor Analysis. Second, to show insight into the effects of the hypothesized relations between levels of seniority, individual actions and ambidexterity (Figure 2), an ANOVA test of mean differences between the levels of seniority was conducted. Following this, to provide more insight into the effects and explained variance, four dummy variables that represent the levels of seniority were included in a series of Structural Equation Models. This type of analysis allowed us to test the significance of the direct and mediation effects hypothesized in the model, and additionally, gave insight regarding the effect sizes and explained variance of ambidexterity. Due to the high correlations between three of the five actions (integration, role expansion and tone setting) the mediating role of these enabling actions was tested in five separate models to avoid issues concerning multicollinearity.

\section{Sample and design}

The survey data were collected from a global Professional Service Firm, (referred to as TalentCo), which provides outsourced HR business services, for example recruitment and selection of staff on behalf of clients, and HR consulting advice. This organization has its headquarters in United Kingdom and employs 1,580 professionals globally. Our questionnaire was sent as a part of the bi-annual company based survey. Out of the 427 employees with management responsibilities, 212 employees responded to the cross-sectional survey, a response rate of $50 \%$. The analysis of missing values revealed no specific pattern. In addition 
we drew on 35 semi-structured interviews with respondents at all levels in TalentCo. These included directors, senior managers, Heads of Client Services, Manager-Consultants, Principal Specialists, Specialists and Administrator-Coordinators. These were a mix of face-to-face and telephone interviews and each of these lasted around an hour and were recorded and transcribed. We asked questions about how they managed ambidexterity and an explanation of the individual actions which they engaged in and how their HRM practices impacted on their ability to do so. The interviews were conducted in phases to allow feedback to the case study company and to check our understanding and progress. We also studied extensive confidential in-house documents and public materials concerning innovations in TalentCo.

\section{Descriptives, development of the measures, test of reliability and validity}

Organizational level (seniority): An absolute measure of job role was included to measure the level of seniority in the organization. There are five levels from low to high:

(1) Administrators - these staff are engaged in back office work to support more senior employees, for example validating references, organising interview schedules and carrying out security checks. Their work involves interaction with junior client employees and is often very operational in nature.

(2) Specialists - these are staff who have specialist knowledge of the client and perhaps a particular sector, for example engineering in the defence sector, and who carry out recruitment activities on behalf of a client. This role is supported by the Administrator and reports to the Principal Specialist.

(3) Principal Specialists - these staff represent TalentCo to the client while on site on a day-today basis and also manage the Specialists and Administrators in their team. They also have 
specialist knowledge and will additionally be engaged in the recruitment of usually more senior staff on behalf of their client.

(4) Manager Consultants - these are more senior staff who provide consulting advice to clients, for example how a large science-based client can recruit more female graduates, rather than being directly involved in the actual recruitment of staff.

(5) Heads of Client Services and Heads of Functions and members of the Leadership Team this group includes Heads of Client Services who are senior managers representing TalentCo to the client at very senior levels. They will take responsibility for the performance of the client account, especially financial performance, and they will lead contract renewal discussions. Heads of Functions have overall responsibility for particular specialist functions such as Finance or Marketing, while the Leadership Team comprises the most senior members of TalentCo including the Chief Executive

Ambidexterity. At TalentCo the employees work for a particular client in project teams. Therefore, the survey items were developed on the basis of literature on ambidexterity, particularly on studies in similar project-based work setting (Lubatkin et al., 2006; Tiwana, 2008; Turner et al., 2016). In addition the items draw on two existing survey measures of ambidexterity (Mom et al., 2007 and Lubatkin et al., 2006). Confirmatory factor analysis confirmed the factor structure to be sufficient (Chi-square $(11)=20.42, p=0.04, \mathrm{CFI}=.99$, TLI $=.98$, RMSEA .06). The wording of the items and standardized factor loadings are included in Appendix 1.

Individual Enabling Actions. The five key enabling actions that support the effective achievement of an ambidextrous balance have been identified by previous case study work 
(Turner et al., 2016). On the basis of this work $^{1}$ an initial series of 25 survey items was developed. This was reviewed by key researchers in the field and a pilot test by MBA students to evaluate the application in a variety of industries reduced the number of items to 15 . The measures included three items for each of the enabling actions tested in TalentCo. Exploratory factor analysis showed five factors were optimal to represent the underlying structure, with all items loading strongest on their designated factor. The items, Geomin Rotated Factor Loadings and significant cross-loadings are presented in Appendix 2. Confirmatory factor analysis of the final factor structure shows a satisfactory fit with the data (Chi-square $(80)=166.24, \mathrm{p}<0.001$, CFI $=.95$, TLI $=.94$, RMSEA .07). Further analysis of the construct revealed that the three dimensions integration, role expansion and tone setting share a relatively high correlation $(\mathrm{r}>$ $.62)$, however a test of a second-order measurement structure is non-significant ( $\Delta$ Chi-square $(4)=7.42, p=.11)$

Table 1 presents the descriptive statistics, means, standard deviations, correlations between the individual enabling actions and ambidexterity. Reliability has been confirmed, however for comparison with previous studies the Chronbach's alphas of the constructs are included in italics on the diagonal of Table 1.

[Include Table 1 about here]

Given our data is cross-sectional and includes self-report survey items the models tested may be affected by common method bias. In the design of our survey we have aimed to decrease common method bias by grouping questions in different sections and separating them by demographics related questions as suggested by Podsakoff, MacKenzie, and Podsakoff

\footnotetext{
1 The process of developing, reviewing, exploring and confirming of the factor structure of this measure is described and reported with the aim to use minimal space in the paper. More detailed information about the factor structure, the loadings and the items are included in Appendix 2. Also a series of tests has been conducted to confirm the factor structure and to test for a second-order latent structure. These showed that the individual enabling actions are related however a second-order factor showed no improvement of the overall fit.
} 
(2012). Prior to analyzing the data, we controlled for common method bias (Podsakoff \& Organ, 1986; Podsakoff, MacKenzie, Lee, \& Podsakoff, 2003). Harman's single-factor test indicated that no single factor emerged from the unrotated factor solutions and that no first factor explained the majority of the variance in the variables. Furthermore, a $\chi 2$-difference test based on confirmatory factor analysis indicated that the single-factor model, in which all manifest variables loaded on a single latent factor, fit the data significantly worse than the multi-factor model, in which all manifest variables loaded on their respective latent factors $(\Delta \chi 2=2324.16 ; \Delta \mathrm{df}=5, \mathrm{p}<.001)$. Therefore, we may conclude common method bias does not constitute an substantial issue in this study.

\section{Results}

\section{Test of the hypothesized model}

The mean differences between the individual enabling actions across the five levels of seniority were standardised and are displayed in Figure 2. The results of the post hoc test of mean equality are included in Appendix 3. Results show an effect between level of seniority and enabling actions in the following way. The more senior the managers are the more they engage in integration, role expansion and tone setting. Gap filling is an action which is performed less by the senior managers and more by the lower level managers. Buffering is mostly undertaken by Principal Specialists. In addition, the Principal Specialists are most balanced in performing all five types of individual enabling actions rather than engaging in one type more than others.

[Include Figure 2 and the table from Appendix 3 about here] 
The mediation effect of enabling actions has been tested through a series of latent mediation models using MPlus software, version 7.2. The standardised paths and explained variance of the five mediation models are presented in Table 2. First the direct effect of level of seniority on ambidexterity is tested in a latent regression model. In the first step both the level of seniority and two control variables are regressed on ambidexterity. The first model includes a latent model in which the direct effect of the four dummy variables of the level of seniority are regressed on the two dependent variables of ambidexterity, explore and exploit. The largest group (i.e., Manager Consultants), is used as the reference category. The model finds that the three more senior levels (dummy variables) have an effect on explore or exploit, from which it may be concluded that these managerial levels have a significant effect on ambidexterity. With the interpretation of these effects it is important to note that they are significant in comparison to the reference group (Manager Consultants). In other words, senior managers (Heads of Services) are more likely to have an exploratory orientation than the Manager Consultants.

In the second step the mediation effects of enabling actions were added to the model, assessing the results for each action separately. The results of this analysis are displayed in Table 2. The mediation effect of the enabling actions is confirmed for role expansion and tone setting, which fully mediate the effect of level of seniority on ambidexterity. Integration also mediates the effect of the individual enabling actions, but there is still a direct effect from the level of seniority (heads) on ambidexterity $\left(\beta=.12^{*}\right)$. Gap filling was not found to mediate the effect between level of seniority on ambidexterity, however it was found to have a positive effect on explore $\left(\beta=.20^{* *}\right)$. Buffering has a direct effect on both explore and exploit (change in explained variance is $\mathrm{R}^{2}=.16^{* *}$ for exploit and $\mathrm{R}^{2}=.18^{* *}$ ), however this enabling action is not affected by the level of seniority. 


\section{Findings and Discussion}

In this section we discuss our findings and pay particular attention to how ambidexterity is achieved within our case study. We then move on to discuss the individual actions which enable this mix of exploration and exploitation by paying particular attention to how the level of seniority impacts on ambidexterity. Finally, we consider the HRM implications and HRM practices that underpin these enabling actions drawing illustrations from TalentCo.

\section{$\underline{\text { Ambidexterity in TalentCo }}$}

The findings indicate that TalentCo engages in ambidexterity through the combination of exploring new knowledge and exploiting and refining existing knowledge. This is an important preliminary condition which enables us to unpick the individual actions which support ambidexterity. The results also show a relationship between the level of seniority and ambidexterity (see Table 2), such that more senior managers within the organizational hierarchy such as the Head of Client Services, Manager Consultants and Principal Specialists, are more likely to engage in exploratory action. This will be expected given that exploratory behaviours call for flexible approaches to solving project issues and a longer-term perspective on addressing client problems. Clearly, these actions would require judgement, experience and authority. This confirms the work of Burgess et al. (2015) who found that these behaviours are needed in hybrid managers such as the Principal Specialists.

In addition this group also shows higher levels of both exploitation and exploration which confirms that more senior employees engage in ambidexterity. In contrast, employees who are employed at the lower levels within the organizational hierarchy, such as the Administrators and Specialists, use less exploration and also are less likely to engage in ambidexterity in general. This may be explained on the basis that staff at these lower levels in 
the organizational hierarchy have more of an operational focus and are more likely to use exploitative behaviours in response to regular client feedback and instructions.

\section{Actions which enable ambidexterity}

The research objective was to understand which individual actions enable ambidexterity at particular levels of seniority in the organisation. Here we standardised the mean differences between the different levels and conducted an ANOVA post hoc test of mean equality (see Figure 2 and Appendix 3). Interestingly, here we find that senior roles engage more in integration, role expansion and tone setting in order to create ambidexterity. A more finegrained explanation of this lies in the nature of these enabling actions. Integration requires an overall, or integrative, knowledge of how the various parts of the client project work together. This is also expressed in needing to understand the 'big picture' or to take a holistic view. These are actions which are developed through extensive experience and an ability to step back from problems in order to generate innovative solutions. This finding supports prior research which speaks of the importance of having 'architectural knowledge' in order to generate exploratory services (Kang, at al., 2012) as well as the work of Andriopoulos and Lewis (2009) who found that integration offered a powerful tactic for fostering ambidexterity. The importance of setting the innovative climate (Prieto and Pilar Pérez Santana, 2012) has been stressed by the Chief Executive of TalentCo:

'For us it means we need to make sure that we really understand future trends and how they are going to impact on the organizations that we are working with and embedded within and ensuring we are anticipating those needs and that we've got appropriate services and appropriate agility built into the solutions in order to support the challenges in the future.'

The particular aspects of role expansion and tone setting reflect the importance of taking responsibility for the duration of the innovation project, i.e. to be the point of contact when any 
problems should arise. This creates a space within which the client project team can be creative without absorbing the immediate client problems and demands. This process of setting the tone or the way of working within the client project team, which often requires psychological safety, has been shown to enable innovation (Nonaka \& Takeuchi, 1995). It also counteracts the typical reactions that Lewis (2000) found which is to be defensive and focusing exclusively on their own role. The Heads of Client Services demonstrate this tone setting well because they provide the link between TalentCo and one or more clients and the employees working on the account.

The findings indicate further that the level of the Principal Specialist is of particular importance in supporting ambidexterity. This is the only role which draws on all the enabling actions whilst working on client projects. This is not surprising because, as we have noted, they have to manage multiple parties within the client and their more senior managers in TalentCo on a day-to-day basis whilst drawing on their specialist skills. They therefore represent the typical hybrid-manager (Burgess et al., 2015). In addition to the actions taken by the Heads of Client Services and the Manager Consultants discussed above, the Principal Specialists also engage in buffering and gap filling which enable the team to continue to be ambidextrous. This group of staff engaged in buffering whereby they created the conditions where their more junior staff could engage in their day-to-day operations effectively, operating within existing procedures (that is exploitative outputs). For example one of these managers exemplified this well noting that their client was 'A very, very demanding customer, so they need you to move and evolve as they do and with speed' but on occasions it was necessary to 'rather than give the client what they are looking for, we have to manage their expectations down.' However, at the same time they also had to manage their relations with senior managers at TalentCo head office. As one said, 'We need to make sure the account is performing first and foremost and at the end of the day we need to make sure we are getting the work done.' This requires not only 
the ability to take responsibility and decisions but it also speaks to the importance of detailed knowledge of the client and the organizational processes and systems. This is aptly expressed in the way in which documentation and processes would be completed when there are any gaps or when processes have been overlooked.

This is also seen in the way in which a Specialist, which is a more junior role, enables ambidexterity. The action that these employees use is that of gap filling. In practice this is a very operational role where the Specialist has direct responsibility for satisfying particular client requirements such as recruiting a new employee on time and within budget. There is clearly a need for detailed client and organizational knowledge to support the innovation process and to create a space within which the client project team can work productively. This supports research on the specificity of human capital (Lepak and Snell, 1999; Swart, 2007) in so far as both client-specific and firm-specific human capital needs to be developed in order to enact gap filling.

The most junior level in our sample, i.e. Administrators, engage specifically in the administrative aspects of gap filling, i.e. documentation and administrative procedures. This indicates that both detailed actions, at junior levels, and strategic actions such as tone setting and integration, at senior levels, are important and complementary to enable ambidexterity.

[Insert Table 3 here]

\section{$\underline{\text { HRM Practices and Implications: an Ambidexterity HRM framework }}$}

The types of individual actions that employees and managers undertake to ensure that the organization is ambidextrous hold important implications for HRM practices (see Table 3). In the section that follows we discuss (i) each individual enabling action (i.e. integration, role expansion, tone setting, buffering and gap filling) and (ii) the HRM practices (resourcing, 
development, performance and reward) which support these actions, illustrating these with evidence from TalentCo.

Firstly, our data indicated that HRM practices are focused on the development of integration, role expansion and tone setting at the senior levels (Head of Client Services, Manager Consultant and Principal Specialist). The HRM practices which support integration are critically important as they enable the organization to accentuate the necessity of embracing both exploration and exploitation (Andriopoulos and Lewis, 2009). These HRM practices also display characteristics of the clan mechanism (Yoon and Chae, 2012) which essentially enable the development of holistic knowledge that is related to the client project. This is often the result of high tenure (Chang, 2015) in a professional services firm (PSF) combined with rotation between different client projects. In particular, HRM practices ensure that the project is resourced with experienced staff who are able to 'see the big picture'. There is also a need to understand both specific client interests and demands and also more general client management processes and 'ways in which to manage client accounts'. Hence performance management and reward practices are focused on the achievement of both PSF and client objectives and typically are more long-term.

The principal way in which TalentCo supports the development of this 'big picture' understanding is through what they refer to as their 'Leadership Academy.' In essence this a development programme aimed at their top 60 managers designed to help them develop a holistic view of the company's activities. In addition there is a sophisticated internal staff mobility programme for the next tier of managers who are moved between clients on a regular basis to develop diverse knowledge and experience. Both of these practices are supported by a comprehensive induction programme for all staff which emphasises the breadth and diversity of client accounts within TalentCo. These 'clan-based' HRM practices therefore create a shared vision (Guttel and Konlechner; 2009) and sense of belonging which is also associated with 
higher tenure as confirmed by Yoon and Chae (2012). The development of a holistic view is also supported by TalentCo's use of a profit sharing scheme in which all staff participate. Here the achievement of company-wide objectives triggers the distribution of part of the profits to all staff the size of which depends on their level of seniority: more senior staff get a larger proportion of profits than more junior staff.

Secondly, role expansion is enabled by HRM practices that are focused on developing managerial and leadership capabilities with an emphasis on accountability in particular. Our data indicate that job design takes experience and responsibility into account. This means that resourcing practices allow for the development of depth of experience which can then be reflected in the sharing of best client relationship management practice. These practices ultimately support the development of successful hybrid-managers (Burgess et al., 2015). Similarly, positive client feedback, which stems from in-depth experience with the client, is recognised in the performance and reward system. In addition role expansion is encouraged through the recognition and reward of discretionary behaviour, or doing more than is required on the project in order to enable ambidexterity. Particular attention was paid to this in TalentCo by increasing the discretion of managers on client sites especially in the areas of performance management and promotion. This allows managers to make decisions in these areas quickly and locally to encourage innovative behaviours. Critically, this broadening of their role has been supported by an extensive range of management development programmes aimed at improving the skills of managers who are not among the top 60 in the company.

The third individual action that supports ambidexterity and is dependent upon the level of seniority is tone setting which enables the senior employee to 'determine the way of doing things' within the client project team. This may be more exploitative or exploratory depending on the particular requirements of the situation and has a direct impact on the innovative climate (Prieto and Pilar Pérez Santana; 2012). Interestingly, this is not purely an individual skill set 
but also the property of the team. That is to say, the client project team members trust the manager to take responsibility for setting the tone (Xing et al., 2016). In this context the resourcing practices ensure that there is a link between the client and the organization. This requires an exposure to client specific practices, or the client-preferred way of implementation. Senior managers therefore spend time with the client or work on the client site in order to set a tone in the team which mirrors the client's operational processes. The notion of 'mirroring' the client is also reflected in the team selection. That is, the project team is staffed with employees with whom the client will identify. Development practices furthermore enable the transfer of client-specific knowledge. Importantly, tone setting is a leadership function and investments are made in the development of leadership skills. The value of the powerful combination of client and project specific knowledge (as the tone is set) is also reflected in performance management and reward practices. Hence, client-specific knowledge is recognised and teamfocused behaviours are rewarded.

TalentCo supported tone setting through the actions of its Leadership Team and the Head of Client Services. The Leadership Team, including the CEO, regularly visited employees on client site to communicate cultural messages and to develop their knowledge of both client and employee issues. In addition Heads of Client Services visited TalentCo staff working on the client site on a regular basis even in an age of electronic communication. One Head of Client Services said, 'The way I do it is I get face time with them; that is the way I have worked out that works.' Others use different mechanisms, including ensuring staff in their teams attend the quarterly meetings held in TalentCo offices, attend training courses and also take part in social events. These face to face methods were supported by the induction programme referred to earlier and the management development programmes. The use of data from their bi-annual employee attitude survey also gave powerful cultural signals about the importance of links between employee attitudes and key measures of performance. The data collected were 
analysed on the basis of each client group and then fed back to Heads of Client Services. These managers were then tasked with understanding the data and putting forward action plans for change. Typically these plans were developed by engaging local TalentCo staff and comparing practices across different client groups.

A fourth critically important individual action which was performed is that of buffering. In this action, the individual who is the main point of contact for the client will literally 'protect' the team from pressures from the client and the PSF in order for other team members to implement necessary tasks which make ambidexterity possible. This requires a detailed knowledge of the organization and the client's processes and preferences. HRM practices are accordingly focused on developing experienced staff and placing them as a key point of contact for the client. In other words the organization develops not only industry, or domain expertise, but also client expertise, which calls for long project tenure (Chang, 2015). Positive client and team feedback as well as client specific knowledge are recognised and rewarded. In TalentCo our data evidenced that Principal Specialists are equipped with client relationship and team management skills through a combination of the staff mobility programme and the management development programmes designed to support the exercise of increased discretion.

The final individual action which enabled ambidexterity and which was performed by principal specialists and more junior employees, e.g. Specialists and Administrators, is that of gap filling. This referred to the ability to literally 'fill in the gaps' in the operational processes of the organization. Here resourcing practices ensure that organization specific knowledge is developed via high tenure on a project. This is often part of a 'career trajectory' wherein more junior staff focus on exploitation via the efficiencies created by operational detail and then progress to intricate client interaction in order to explore. The superior-subordinate relationship is therefore critical in enabling ambidexterity over time (Xing et al., 2016). The development 
practices are therefore focused on the transfer of both tacit and explicit knowledge of operational processes. This is made possible through formal training but also via informal mentoring within the project team. It is subsequently important to recognise and reward operational knowledge as well as the ability to 'think creatively' when projects need to be completed according to specification.

One key way of supporting gap filling in TalentCo is through the development of client and firm specific human capital facilitated by a comprehensive web based knowledge database which is open to all employees but is particularly useful for more junior staff. This gives easy access to all the firm's documents and procedures and also allows for the sharing of best practice between the different client accounts. This provides a valuable resource for the hard pressed member of junior staff under pressure from their client to solve a problem quickly at short notice.

In our further analysis we sought to understand which individual actions explained the greatest proportion of variance in ambidexterity. As presented in the previous section we find that four out of the five individual actions have a significant effect on ambidexterity with integration explaining most of the variance of ambidexterity. A total of $41 \%$ of the variance of exploitation and $30 \%$ of the variance of exploration can be attributed to integration, which is explained variance in addition to the effects of the control variables and the level of seniority. It can therefore be regarded as the central and pivotal action which ensures innovation. In this context it is important to note that the most senior employees, at the highest level in the organizational hierarchy draw upon integration to innovate. This supports Andriopoulos and Lewis' (2009) notion that integration is ultimately important to manage the paradox of ambidexterity. As discussed above, integration relies on the ability to 'see the big picture' and also 'how the various parts of the project work together'. This finding supports earlier qualitative work which found integration to be the centre from which other actions extended 
(Turner et al., 2016). It is therefore of paramount importance that HRM interventions are directed toward the development of these skills which allow for the balance between exploration and exploitation.

In addition, as presented in the previous section, we tested the mediation effect of the enabling actions through a series of latent mediation models (a complete overview of the standardised paths of the five mediation models is provided in Table 2). The findings indicate that both role expansion and tone setting completely mediated the relationship between level of seniority and ambidexterity. Heads of Client Services and Manager Consultants are more likely to use these actions due to their level of seniority. These individual enabling actions are role dependant and it is therefore more challenging to increase their use by more junior employees. This holds implications for client project resourcing, job design and development. The findings indicate that if a client project demands that the organization engages in both exploratory (renewed) and exploitive (refined) behaviours then it is important to ensure that there are appropriate senior employees to guide the project processes. In terms of job design and development these managers and consultants would need to have a holistic perspective of client demands and project processes. This means that these roles/jobs cannot be designed in narrow ways and should allow for greater degrees of flexibility and freedom. It also emphasises the importance of senior employees 'developing the bigger picture' through a series of project rotations and also via the sharing of best practice with their peers.

The requirement to invest in the development of role expansion and tone setting therefore has knowledge-specific implications which further calls for strategic links between knowledge management processes and people management processes. Indeed, it is common practice for senior members in our case study organization to record best practice and to meet frequently to discuss how they approach client solutions. This is done in face to face meetings as well as through the use of technology. 
In our further tests of mediation we found that gap filling did not mediate the impact level of seniority on ambidexterity. As presented above, gap filling did have a positive effect on exploratory behaviours $\left(\beta=.20^{* *}\right)$. In this context it is important to take note that both Principal Specialists and Specialists engage in gap filling when working on projects. This needs to be considered in the light of clients who demand highly innovative outcomes only, i.e. exploration and not exploitation. The findings indicate that if this is the case, then it would be in the organization's interest to resource the client project team with sufficient experienced Principal Specialists and to provide them with the opportunity to create consistency and completion of operational processes in order to enable exploration.

The individual action of buffering was not found to mediate the relation between level of seniority and ambidexterity. However, a direct effect on both exploration and exploitation was found independent of level of seniority. This direct relationship together with the analysis presented in Figure 1 and Appendix 3 indicates that specialist knowledge is central to the direct enablement of innovation, i.e. the combination of exploration and exploitation. This is expressed by the presence of buffering in the role of Principal Specialist only. Here both management practices, such as being the point of contact, as well as a more holistic understanding of how team members need to work together, i.e. the ability to focus on their areas of expertise, are important.

This indicates that if client projects require both small refinements (exploitation) and more significant changes (exploration) then it is important to invest resources in the development of both client specific knowledge, i.e. being the expert, as well as the ability to manage both the client and the team. There is therefore an intricate interplay between managing internally as well as externally, i.e. the client relationship. 
We have discussed our main findings as well as their implications for HRM practices such as resourcing, job design and development. In the section that follows we conclude these findings and discussion and consider implications for both theory and practice. Finally we consider avenues for future research.

\section{Conclusions}

In this paper we developed an understanding of the individual actions which enable ambidexterity at specific levels of seniority within the organization. In this context we emphasised that unless we create a better understanding of these individual enabling actions across various levels we cannot begin to develop theory that links HRM to ambidexterity (Junni et al., 2015). In order to meet this need we asked: 'Which individual actions are undertaken by employees at particular levels of seniority in the organization to enable ambidexterity?'

We found that employees at senior levels in the organizational hierarchy tend to engage in integration, role expansion and tone setting. This points to the need to develop holistic knowledge or a big picture which in turn calls for specific job design and development approaches. In addition we discussed the importance of specialist knowledge, both of the firm and the client, when seeking to achieve ambidexterity. Finally, we considered mediation effects on the relationship between levels of seniority and ambidexterity. This enabled us to illustrate the importance of role expansion and tone setting. These actions require both in-depth experience of the organization and the client and call for flexibility and the freedom to judge how to engage in ambidexterity.

In each section of the discussion we considered the implications for HRM practices and in the conclusions we reflect on this framework of HRM practices that support ambidexterity. It is important to note that the HRM practices that are needed at senior levels in the organisation are akin to the characteristics of HPWS, especially the focus on recruitment for potential, job 
rotation and development (Chang, 2015) and the clan-based mechanism identified by Yoon and Chae (2012). At the more junior levels of the organisation gap filling was an important individual action which enabled mainly ambidexterity. The HRM practices which facilitate gap filling, as discussed above, show similarities with more bureaucratic HRM systems. The coexistence of these two HRM systems within the organization, i.e. clan-based mechanisms at the senior levels and bureaucratic-based mechanisms at more junior levels in the organisation calls for an organisational capability to manage a paradox which is so inherent in ambidexterity theory (Lewis, 2000). The practices, which we presented in Table 3, therefore illustrate the fine-grained content of an HRM framework that does enable ambidexterity. This makes a clear contribution to the HRM literature in so far as it provides detailed empirical evidence of HRM practices, which enable ambidexterity through individual actions.

This study has several limitations. Our data come from one organization, and are crosssectional and self-reported. While these three aspects of our data might limit causal inferences and generalisability (Taris and Kompier 2006), they do not invalidate our findings (Kline, Sulsky and Rever-Moriyama 2000). Particularly in this case we have found differences in the effects to be significant for some individual actions and not for others. Studies severely biased by the use of common methods show all concepts to be significantly related to one another without a difference between the effects. Future longitudinal studies may provide more insights into the causal and interactive nature of the relations in our study over time.

It would be useful to apply our findings on the individual actions that enable ambidexterity across a variety of industries, sizes and growth phases of organizations. Replication and extension of the model may be particularly of value in relation to the newly developed measure of individual actions, which will need to be validated across a variety of organizations in various industries in an international context. This could be strengthened by gathering data on the client's perspective of the ambidextrous outcomes. Finally, a more 
detailed study could include measures of these individual enabling actions in a dynamic way which could also then provide insight into how ambidexterity unfolds over time.

In summary, we have argued for the need not only to understand which individual actions enable ambidexterity but also to pinpoint how these actions differ across the organizational hierarchy, i.e. at various levels of seniority. We have been able to illustrate in a fine-grained manner, who (level of seniority) does what (the individual enabling actions). This enabled us to develop an HRM framework that enables ambidexterity via individual actions. It therefore speaks directly to the links between HRM and ambidexterity by pinpointing which individual actions need to be managed in order to secure ambidexterity. 


\section{References}

Ahammad, M.F., Lee, S.M. and Malul, M., and Shoham, A. (2015) Behavioural Ambidexterity: The impact of incentive schemes on productivity, motivation, and performance of employees in commercial banks. Human Resource Management: 54 $\mathrm{S}(1): \mathrm{S} 45-\mathrm{S} 62$

Andriopoulos, C. and Lewis, M. (2009). Exploitation-exploration tensions and organizational ambidexterity: Managing paradoxes of innovation. Organization Science, 20, 696717.

Birkinshaw J. and Gupta K. (2013). Clarifying the Distinctive Contribution of Ambidexterity to the Field of Organization Studies. Academy of Management Perspectives, 27 (4) 287298.

Burgess, N., Strauss, K., Currie, G. and Wood, G. (2015). Organizational ambidexterity and the hybrid middle manager: The case of patient safety in UK hospitals. Human Resource Management, 54 (S1) S87-S109.

Caniels, M.C.J., \& Veld, M. (2016). Employee ambidexterity, high performance work systems and innovative work behaviour: How much balance do we need? The International Journal of Human Resource Management, DOI: 10.1080/09585192.2016.1216881

Cegarra-Navarro, J. G. and Dewhurst, F. (2007). Linking organizational learning and customer capital through an ambidexterity context: an empirical investigation in SMEs. International Journal of Human Resource Management. 18 (10) 1720-1735.

Chang, Y.-Y. 2015. A multilevel examination of high-performance work systems and unitlevel organizational ambidexterity. Human Resource Management Journal, 25 (1), 79 101.

De Clercq, D., Thongpapanl, N. and Dimov, D. (2014). Contextual ambidexterity in SMEs: the roles of internal and external rivalry. Small Business Economics, 42 (1) 191-205.

De Clercq, D., Thongpapanl, N. and Dimov, D. (2013). Shedding new light on the relationship between contextual ambidexterity and firm performance: An investigation of internal contingencies. Technovation, (33) 4/5, 119-132.

Dixon, S.E.A., Meyer, K.E., and Day, M. 2007. Exploitation and exploration learning and the development of organizational capabilities: A cross-case analysis of the Russian oil industry. Human Relations, 60 (10), 1493-1523.

Dover, P. A. and Dierk, U. (2010). The ambidextrous organization: integrating managers, entrepreneurs and leaders. Journal of Business Strategy, 31(5) 49-58.

Fisit J. and Dostaler I. (2013) Combining old and new tricks: ambidexterity in aerospace design and integration teams. Team Performance Management, 19 (7/8) 314-330.

Garaus, C., Güttel, W., Konlechner, S., Koprax, I., Lackner, H., Link, K. and Müller, B. (2016) Bridging knowledge in ambidextrous HRM systems: empirical evidence from hidden champions. International Journal of Human Resource Management. 27 (3) 355-381.

Gibson, C. B. and Birkinshaw, J. (2004). The Antecedents, Consequences, and Mediating Role of Organizational Ambidexterity. Academy of Management Journal, 47(2) 209-226.

Güttel, W. H. and Konlechner, S. W. (2009), Continuously Hanging by a Thread: Managing Contextually Ambidextrous Organizations. Schmalenbach Business Review, 61 (2) $150-172$.

Havermans, L.A., Den Hartog, D. N., Keegan, A. and Uhl-Bien, M. (2015) Exploring the Role of Leadership in Enabling Contextual Ambidexterity. Human Resource Management 54, S179-P200. 
Heavey, C., Simsek, Z. and Fox, B.C. (2015) Managerial Social Networks and Ambidexterity of SMEs: The Moderating Role of a Proactive Commitment to Innovation. Human Resource Management. 54, S201-S221.

Huang, J. and Kim, H. J. (2013) Conceptualizing structural ambidexterity into the innovation of human resource management architecture: the case of LG Electronics. International Journal of Human Resource Management, 24 (5) 922-943.

Janssen, O., van de Vliert, E., and West, M. (2004). The bright and dark sides of individual and group innovation: a Special Issue introduction. [Editorial Material]. Journal of Organizational Behavior, 25(2), 129-145.

Junni, P., Sarala, R.M. Taras, V. and Tarba, S.Y. (2013). Organizational Ambidexterity and Performance: a Meta-Analysis. Academy of Management Perspectives, 27 (4) 299-312

Junni, P., Sarala, R.M., Tarba, S.Y., Liu, Y. and Cooper, C.L. (2015) Guest Editors' Introduction: The Role of Human Resources and Organizational Factors in Ambidexterity. Human Resource Management, 54, S1-S28.

Kang, S-C., Morris, S. S. and Snell, S. A. (2007). 'Relational archetypes, organizational learning and value creation: extending the human resource architecture'. Academy of Management Review, 32, 236-56.

Kang, S-C. and Snell, S.A. (2009). Intellectual capital architectures and ambidextrous learning: a framework for human resource management. Journal of Management Studies, 46 (1), 65-92.

Kang, S., Swart, J., and Snell, S. (2012). Options-based HRM, Intellectual capital and exploratory and exploitive learning in Law Firm's Practice Groups. Human Resource Management, 51(4), 461-485

Ketkar, S. and Sett, P. K. (2009). HR flexibility and firm performance: analysis of a multi-level causal model. International Journal of Human Resource Management. 20 (5) 10091038.

Kline, T. J. B., Sulsky, L. M., and Rever-Moriyama, S. D., (2000), 'Common Method Variance and Specification Errors: A Practical Approach to Detection', Journal of Psychology, 134, 401-421.

Kostopoulos, K.C., Bozionelos, N. and Syrigos, E. (2015) Ambidexterity and Unit Performance: Intellectual Capital Antecedents and Cross-Level Moderating Effects of Human Resource Practices. Human Resource Management, 54, S111-S132.

Lepak, D. and Snell, S.A. (1999). The strategic management of human capital': determinants and implications of different relationships. Academy of Management Review, 24 (1) 118.

Levinthal, D.A. and March, J.G. (1993). The myopia of learning. Strategic Management Journal, 14, 95-112.

Lewis, M.W. (2000) Exploring paradox: Toward a more comprehensive guide. Academy of Management Review. 25: 760-776

Li, Q., Maggitti, P., Smith, K., Tesluk, P. and Katila, R. (2013). Top management attention to innovation: the role of search selection and intensity in new product introductions. Academy of Management Journal, 56 (3) 893-916.

Lubatkin, M. H., Simsek, Z., Ling, Y. and Veiga, J. F. (2006). Ambidexterity and Performance in Small- to Medium-Sized Firms: The Pivotal Role of Top Management Team Behavioral Integration. Journal of Management, 32(5) 646-672.

March, J. G. (1991). Exploration and Exploitation in Organizational Learning. Organization Science, 2(1) 71-87.

Mom, T. J. M., Van den Bosch, F. and Volberda, H. W. (2007). Investigating Managers' Exploration and Exploitation Activities: The Influence of Top-Down, Bottom-Up, and Horizontal Knowledge Inflows. Journal of Management Studies, 44(6) 910-931. 
Mom, T. J. M., Van den Bosch, F. and Volberda, H. W. (2009). Understanding Variation in Managers' Ambidexterity: Investigating Direct and Interaction Effects of Formal Structural and Personal Coordination Mechanisms. Organization Science, 20 (4) 812828.

Napier, N. P., Mathiassen, L. and Robey, D. (2011). Building contextual ambidexterity in a software company to improve firm-level coordination. European Journal of Information Systems. 20 (6) 674-690.

Nemanich, L. A. and Vera, D. (2009). Transformational leadership and ambidexterity in the context of an acquisition. Leadership Quarterly. 20(1) 19-33.

Nonaka, I. and Takeuchi, H. (1995). The knowledge-creating company. Oxford University Press, Oxford

O'Reilly, C. A. and Tushman, M. L. (2004), The Ambidextrous Organization. Harvard Business Review. 82(4) 74-81.

O Reilly, C.A. and; Tushman, M.L. (2013). Organizational Ambidexterity: Past, Present, and Future. Academy of Management Perspectives 27 (4) 324-338.

O'Reilly, C.A. and Tushman, M.L., (2011). Organizational ambidexterity in action: how managers explore and exploit. California Management Review 53 (4) 5-22.

Patel, P.C., Messersmith, J.G. and Lepak, D.P. (2013). Walking the tight-rope: an assessment of the relationship between high performance work systems and organizational ambidexterity. Academy of Management Journal, 56 (5), 1420-1442.

Prieto, I. M. and Pilar Pérez Santana, M. (2012). Building ambidexterity: The role of human resource practices in the performance of firms from Spain. Human Resource Management. 51 (2), 189-211.

Prieto-Pastor, I. and Martin-Perez, V., (2015) Does HRM generate ambidextrous employees for ambidextrous learning? The moderating role of management support. International Journal of Human Resource Management. 26 (5) 589-615

Raisch, S. and Birkinshaw, J. (2008). Organizational ambidexterity: antecedents, outcomes, and moderators. Journal of Management. 34 (3) 375-409.

Renzl B., Rost M. and Kaschube J. (2013). Facilitating ambidexterity with HR practices - a case study of an automotive supplier. International Journal of Automotive Technology \& Management, 13 (3) 257-272.

Scott, R. K. (1995). Creative employees - A challenge to managers. Journal of Creative Behavior, 29(1), 64-71.

Seshadri B.S., Piderit S.K. and Giridharadas R. (2010). How many minds does a team have? Contextual Ambidexterity and Goal Harmony in Healthcare. Academy of Management Annual Meeting Proceedings. 2010, p1-6.

Swart, J., and Kinnie, N (2014) Re-considering boundaries: Human Resource Management in a networked world. Human Resource Management, 53(2) 291-310

Swart, J. (2007). HRM and Knowledge Workers in The Oxford Handbook of Human Resource Management. P. Boxall, J. Purcell and P. Wright. (Eds.), Oxford: Oxford University Press.

Tiwana, A. (2008). Do bridging ties complement strong ties? An empirical examination of alliance ambidexterity. Strategic Management Journal. 29 (3) 251-272.

Turner, N., and Lee-Kelley, L. (2013). Unpacking the theory on ambidexterity: An illustrative case on the managerial architectures, mechanisms and dynamics. Management Learning, 44 (2) 179-196.

Turner, N., Swart, J., and Maylor, H. (2013). Mechanisms for managing ambidexterity: a review and research agenda. International Journal of Management Reviews, 15(3) 317332. 
Turner N., Swart J., Maylor H. and Antonacopoulou E. (2016) 'Making it happen: how managerial actions enable project-based ambidex, Management Learning, 47 (2) 199222.

Tushman, M. L. and O'Reilly, C. A. (1996). Ambidextrous Organizations: Managing Evolutionary and Revolutionary Change. California Management Review. 38(4) 8-30.

Wang C. and Rafiq M. (2014) Ambidextrous Organizational Culture, Contextual Ambidexterity and New Product Innovation: A Comparative Study of UK and Chinese High-tech Firms. British Journal of Management, 25 (1) 58-76.

Yoon, S. J. and Chae, Y. J. (2012). Management of paradox: a comparative study of managerial practices in Korean and Japanese firms. International Journal of Human Resource Management. 23 (17), 3501-352.

Xing, Y., Liu, Y., Tarba, S. Y., and Wood, G. 2015. A Cultural Inquiry into Ambidexterity In Supervisor-Subordinate Relationship. The International Journal of Human Resource Management, DOI: 10.1080/09585192.2015.1137619. 
兽

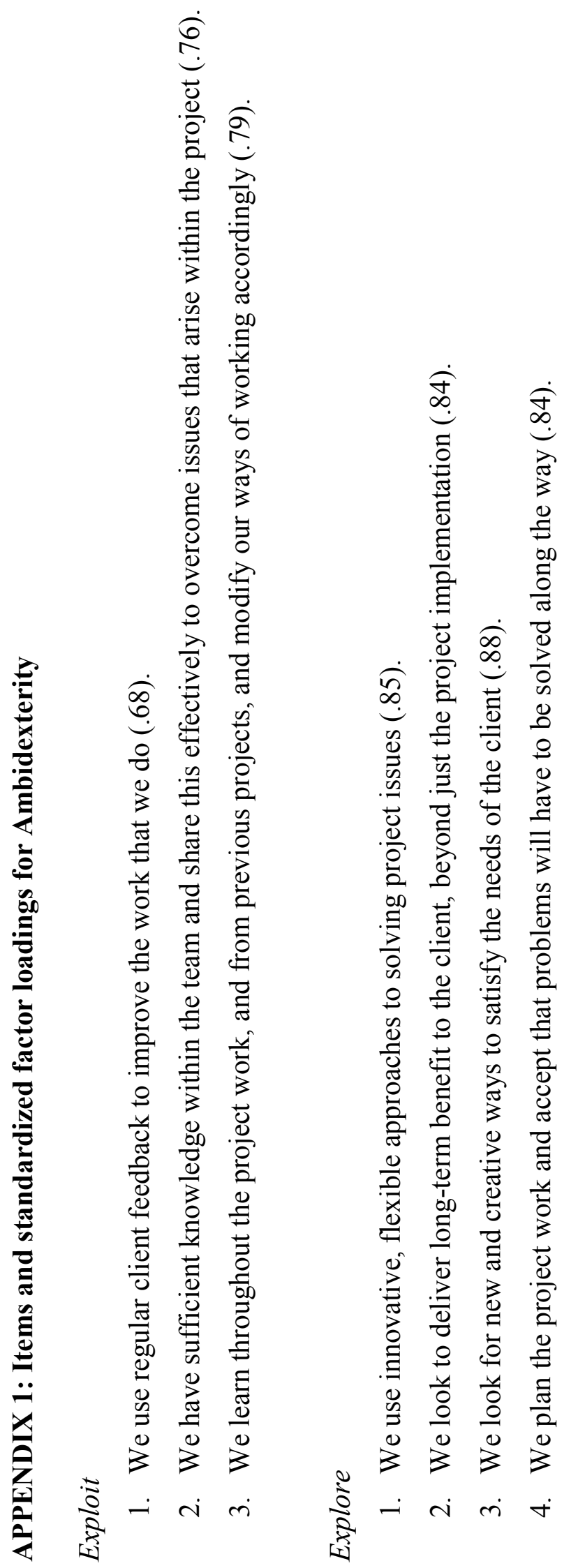




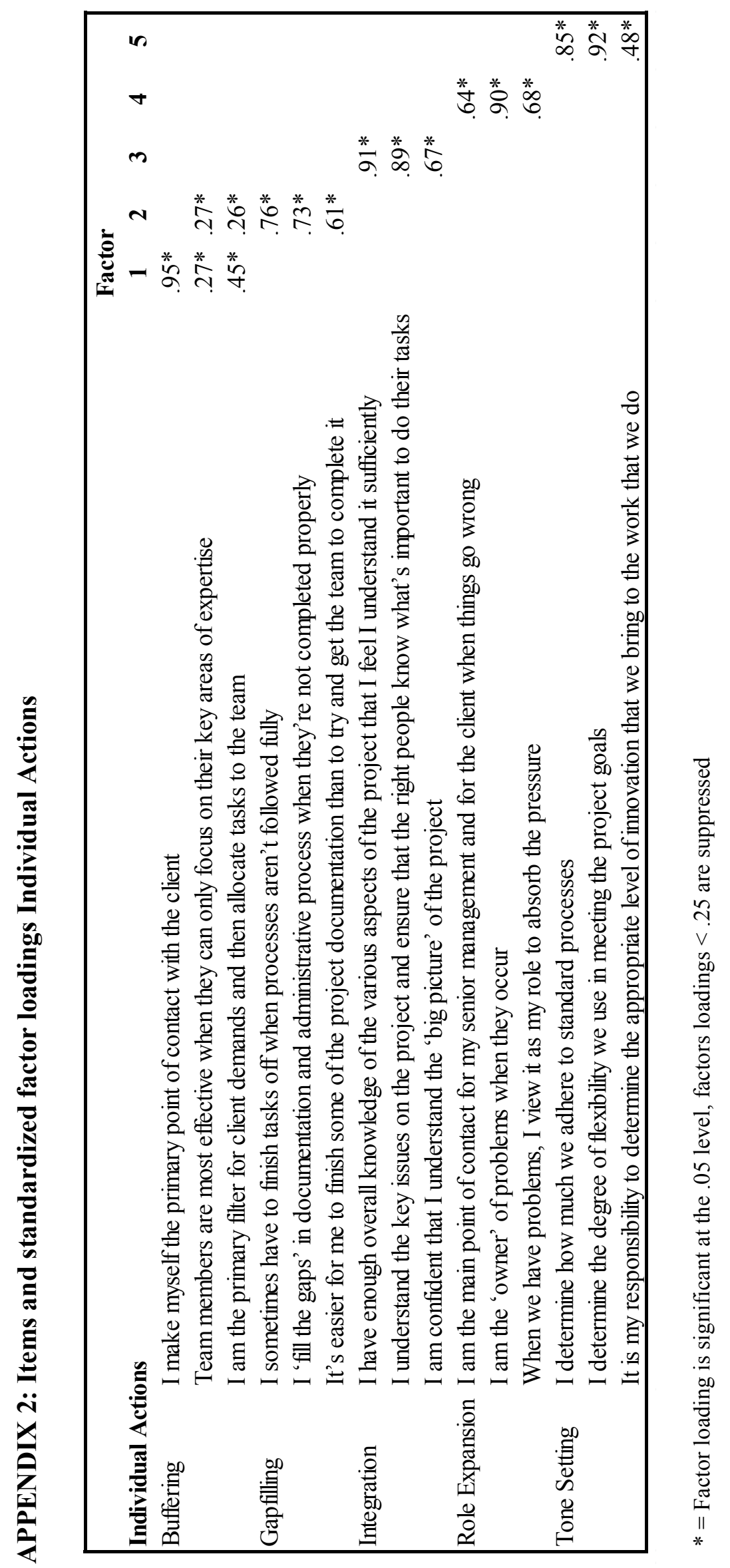




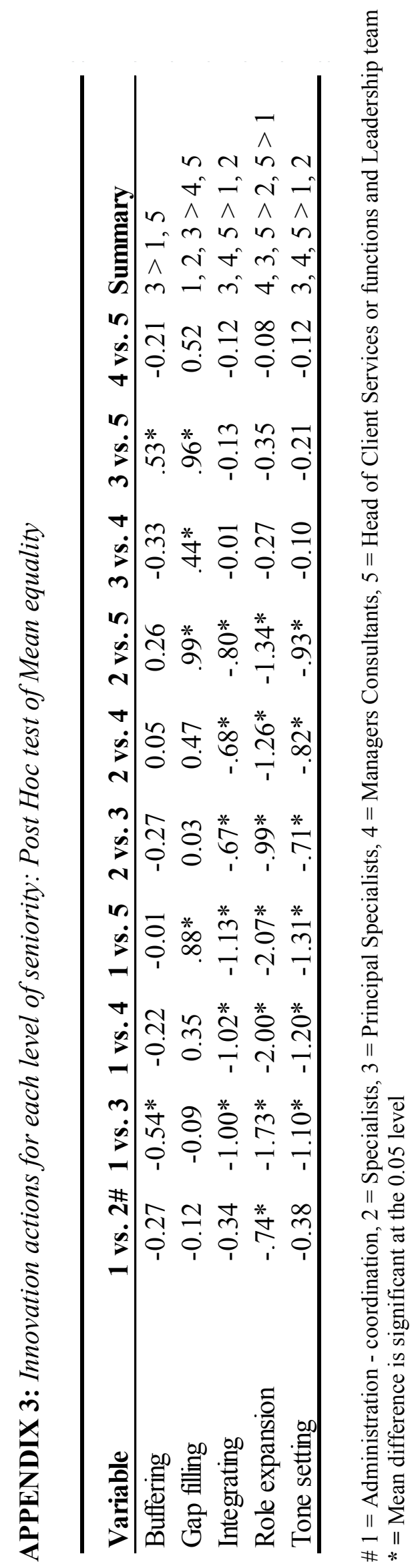




\section{FIGURES}

FIGURE 1: Hypothesized Model

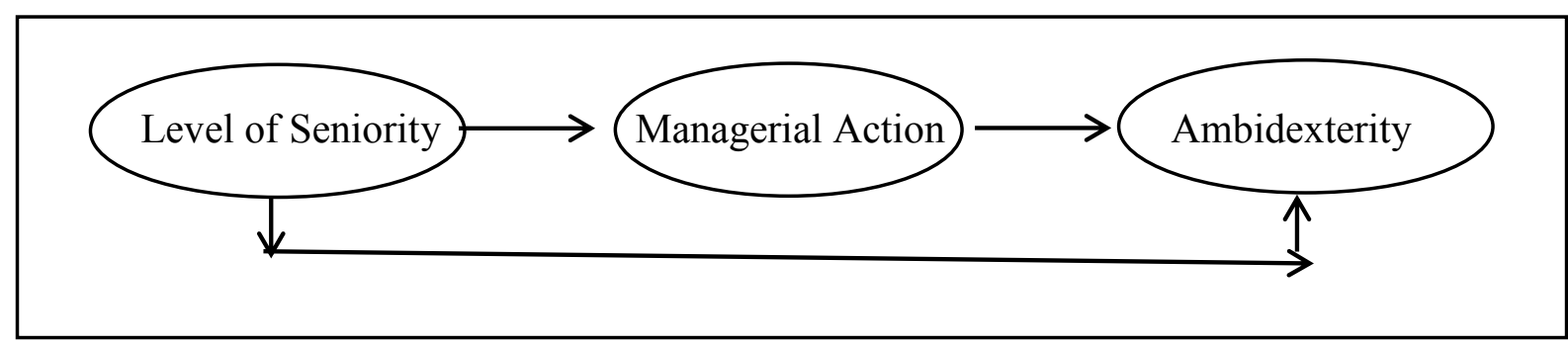

Fig

ure 1 
FIGURE 2: Standardized means of Managerial actions for each of the Managerial levels

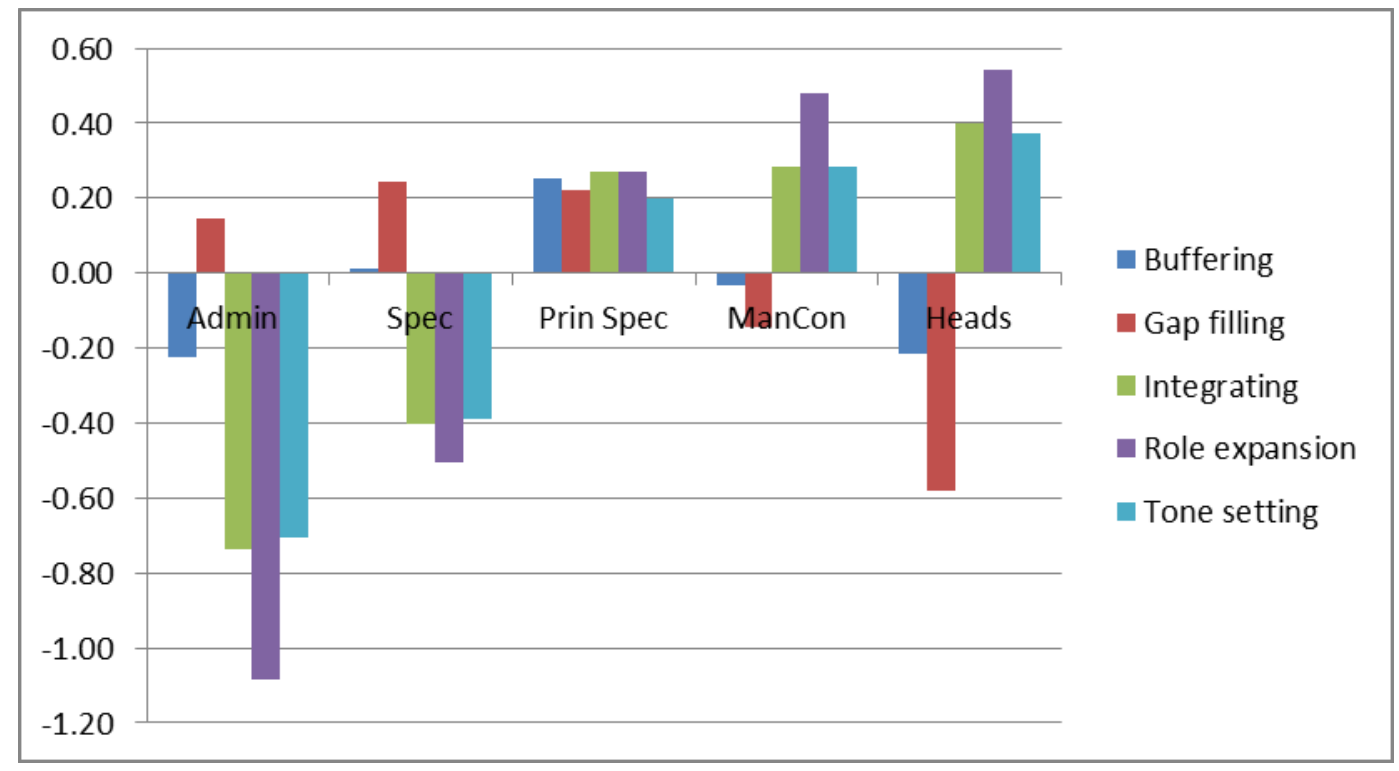

Figure 2

*Admin $=$ Administrators and coordinators, Spec $=$ Specialists, Prin Spec $=$ Principal Specialists, ManCon $=$ Managers Consultants, Heads $=$ Head of Client Services or functions or Leadership team . 
